\title{
PENGARUH KECEPATAN HOMEGENISASI TERHADAP SIFAT FISIKA DAN KIMIA KRIM NANOPARTIKEL DENGAN METODE HIGH SPEED HOMOGENIZATION (HSH)
}

\section{The Influence of Speed Homegenize on Physical and Chemical Properties of Nanoparticle Cream by Using High Speed Homogenization (HSH) Method}

Galuh Suprobo* dan Dwinna Rahmi**

* Institut Pertanian Bogor, Jl. Raya Darmaga Kampus IPB Darmaga Bogor 16680

**Balai Besar Kimia dan Kemasan, Jl. Balai Kimia No. 1 Pekayon Pasar Rebo, Jakarta 13069

**e-mail:dwinna2002@yahoo.com

\begin{abstract}
ABSTRAK
Krim nanopartikel merupakan pengembangan nanoteknologi di bidang kosmetik untuk meningkatkan fungsi krim tersebut. High speed homogenization $(\mathrm{HSH})$ merupakan salah satu metoda dalam pembuatan krim nanopartikel. Pada penelitian ini, krim nanopartikel dibuat menggunakan bahan baku alami turunan kelapa sawit yaitu asam stearat, setil alkohol, setil stearil alkohol dengan metoda HSH. Variabel kecepatan homogenisasi pada $1000 \mathrm{rpm}, 1500$ rpm, 2000 rpm dan 2500 rpm dimaksudkan untuk mengetahui pengaruh kecepatan terhadap sifat-sifat krim. Hasil penelitian menunjukkan bahwa perubahan kecepatan homogenisasi dalam reaktor berpengaruh terhadap tampilan fisik dari segi tekstur, akan tetapi tidak mempengaruhi terhadap kehomogenan, stabilitas dan warna krim. Dari pengamatan selama 2 bulan penyimpanan diketahui tidak terjadi perubahan $\mathrm{pH}$ selama penyimpanan untuk keempat variabel. Ukuran partikel semakin meningkat pada variabel homogenisasi $2000 \mathrm{rpm}$ dan 2500 rpm. Ukuran partikel krim yang dihasilkan berkisar antara 239,86-358,10 nm yang termasuk kategori nanopartikel yang berkisar antara $50 \mathrm{~nm}$ sampai $1000 \mathrm{~nm}$. Stabilitas emulsi dari krim nanopartikel yang dihasilkan berkisar antara $97,20 \%$ sampai $98 \%$.
\end{abstract}

Kata Kunci: Krim nanopartikel, kosmetika, high speed homogenization, bahan baku alami, kecepatan homogenisasi

\begin{abstract}
Nanoparticle cream is the development of nanotechnology in cosmetics fields for improving the function of cream. High speed homogenization (HSH) is one of the methods for creating nanoparticle cream. In this research, the use of natural materials based palm oil derivative such as stearic acid, cetil alcohol, cetil stearil alcohol was chosen in nanoparticle cream producing by using HSH methods. The speed variable of homogenization of $1000 \mathrm{rpm}, 1500 \mathrm{rpm}, 2,000 \mathrm{rpm}$ and 2,500 rpm intended to find out the influence of speed toward the properties of cream product. The observation result showed the influence on physical display in term of texture but not in homogeneity, stability and cream color. The $\mathrm{pH}$ of the product during two months storage for all variables were still stable. The particle size was increased in the homogeneity of speed at $2000 \mathrm{rpm}$ and $2500 \mathrm{rpm}$. In this research had been produced the cream in particle size from 239.86 to $358.10 \mathrm{~nm}$ which enter in nanoparticle category $50 \mathrm{~nm}$ to $1000 \mathrm{~nm}$. The stability of nanoparticle cream product in the range of 97,20 to $98 \%$.
\end{abstract}

Keywords: Nanoparticle cream, cosmetic, high speed homogenization, natural material, speed homogenization 


\section{PENDAHULUAN}

Krim merupakan salah satu kosmetik yang diformulasikan sedemikian rupa untuk merawat tubuh sesuai dengan tujuan penggunaan kosmetika tersebut. Dalam rangka meningkatkan fungsi kosmetik, perkembangan teknologi seperti bioteknologi, nanoteknologi ikut berperan untuk menghasilkan kosmetik yang berdayaguna tinggi. Perkembangan nanoteknologi bidang kosmetik fokus pada sistem koloid (colloidal system) termasuk nanoemulsi, nanosuspensi, dan nanopartikel. Secara umum nanopartikel didefinisikan sebagai partikel dengan ukuran 1-100 nm. Skala ukurannya yang sangat kecil mengakibatkan nanopartikel memiliki luas permukaan per unit volume yang besar sekali, perbandingan atom dalam lapisan permukaan yang tinggi, dan kemampuan untuk menunjukkan efek kuantum (Thassu et al., 2007; Nagarajan, 2008).

Produk nanopartikel mulai dikembangkan pada awal tahun 1990 sebagai alternatif sistem pembawa untuk emulsi, liposom, dan polimer nanopartikel (Pardeike et al., 2009). Penelitian nanopartikel sedang berkembang pesat karena dapat diaplikasikan secara luas seperti dalam bidang lingkungan, elektronik, optis, dan biomedis. Beberapa ukuran partikel pada bahan kosmetik dan obat, seperti coarse partikel yaitu lebih kecil dari $10 \mu \mathrm{m}$, fine partikel yaitu lebih kecil dari $2,5 \mu \mathrm{m}$, ultrafine partikel yaitu lebih kecil dari $0,1 \mu \mathrm{m}$, nanopartikel yaitu $1 \mathrm{~nm}$ hingga 100 $\mathrm{nm}$ juga termasuk $200 \mathrm{~nm}$ hingga $300 \mathrm{~nm}$ ( A S T M C o m m it te e E 56 o n Nanotechnology). Penerapan nano teknologi sudah berkembang ke inovasi bahan kosmetik dan system drug delivery. Adanya teknologi nano, target untuk mengantarkan bahan aktif pada kosmetik dan obat lebih tepat ke sasaran dengan efek samping yang kecil (Menhnert \& Mader, 2001; Medha et al., 2012; Awad et al., 2008).

Salah satu produk teknologi nano di bidang kosmetika dan farmasi adalah krim nanopartikel. Menurut Ansel (2005), krim didefinisikan sebagai campuran dari dua fasa (fasa minyak dan fasa air) yang tidak dapat bercampur, yang distabilkan dengan sistem emulsi dan jika ditempatkan pada suhu ruang berbentuk padat dan mengandung fase minyak lebih banyak daripada fase airnya. Emulsi ini terdiri dari 2 jenis, yaitu tipe air dalam minyak (A/M) atau minyak dalam air (M/A). Sifat umum krim adalah mampu melekat pada permukaan tempat pemakaian dalam waktu cukup lama sebelum krim ini dicuci atau dihilangkan. Krim dapat memberikan efek mengilap, berminyak, melembabkan, dan mudah tersebar merata, mudah berpenetrasi pada kulit (Anwar, 2012). Krim lebih disukai dibandingkan salep karena daya tarik estetiknya, mudah menyebar dengan rata, mudah diserap ke dalam kulit jika digosokkan, mampu melekat pada permukaan kulit dalam waktu yang cukup lama serta mudah dicuci (Lachman et al., 2008). Krim nanopartikel mempunyai keunggulan dibandingkan dengan krim biasa dilihat dari segi ukuran partikelnya. Menurut Awad et al., (2008), kecilnya ukuran partikel akan meningkatkan luas permukaaan yang menyebabkan kelarutan tinggi. Tingginya kelarutan memudahkan partikel tersebut untuk diserap oleh tubuh.

Metode pembuatan krim nanopartikel di antaranya: high speed homogenization $(\mathrm{HSH})$, high pressure homogenization $(\mathrm{HPH})$, ultrasound, solvent emulsification (SE), solvent injection/solvent displacement dan membrane contractor (Müller et al., 2007). Pembuatan krim nanopartikel dengan metode ultrasound dengan kapasitas $50 \mathrm{~mL}$ dengan diamater getar < $10 \mathrm{~mm}$ dapat menghasilkan krim dengan ukuran mencapai $51,4 \mathrm{~nm}$, namun metoda ini tidak dapat di scale up untuk skala industri karena terjadi penurunan daya getar pada diamater besar (Rahmi et al., 2013). Pada penelitian ini metode high speed homogenization (HSH) menggunakan Reaktor PPI (Pressure Products Industries) dipakai untuk menghasilkan krim nanopartikel. Krim nanopartikel sebenarnya dapat dibuat secara konvensional dengan menggunakan mixer. Akan tetapi pembuatan krim untuk skala produksi yang lebih besar membutuhkan suatu alat yang tentunya dapat menampung bahan dengan kapasitas besar. Penggunaan Reaktor PPI dalam pembuatan krim nanopartikel akan membuat proses produksi lebih efektif dan efisien. Perlakuan perbedaan kecepatan homogenisasi pada 
Reaktor PPI dalam penelitian ini untuk mengetahui pengaruh kecepatan homogenisasi terhadap ukuran partikel dan stabilitas emulsi.

\section{METODOLOGI PENELITIAN}

Bahan yang digunakan adalah asam stearat $100 \mathrm{~g}$, setil alkohol $7.5 \mathrm{~g}$, setil stearil alkohol $7.5 \mathrm{~g}$, gliserin $50 \mathrm{~g}$, minyak zaitun $5 \mathrm{~g}$ yang diperoleh dari PT. Indokimika Jayatama Indonesia (Ecogreen Oleochemicals Indonesia). Air demineral $325 \mathrm{~g}$ dan pengemulsi trietanolamin (TEA) 5 $\mathrm{g}$ dari Bratachem Indonesia.

Alat-alat yang digunakan adalah seperangkat alat kaca, neraca analitik, oven, mikroskop, Mixer merk Labortechnik dipakai untuk pembuatan krim konvensional, Reaktor PPI (Pressure Products Industries), dan particle size analyzer (PSA) merk VASCO.

\section{Pembuatan Krim Nanopartikel dengan Metode High Speed Homogenization (HSH)}

Penelitian ini menggunakan bahanbahan alami yang terdiri dari campuran fase minyak dan fase air yang ditambahkan bahan pengemulsi. Komposisi bahan yang digunakan dalam pembuatan krim sesuai dengan proses pembuatan krim berdasarkan Balsam et al., (1972) yang telah dimodifikasi oleh pihak peneliti dari Balai Besar Kimia dan Kemasan (Rahmi et al., 2013). Prinsip pembuatan krim adalah memanaskan fase air dan fase minyak di tempat yang berbeda lalu dicampurkan pada satu wadah. Fase lemak yang berupa asam stearat, setil alkohol, dan setil stearil alkohol ditimbang dengan neraca analitik lalu dimasukkan ke dalam suatu gelas piala besar menjadi satu campuran. Campuran fase lemak tersebut dicairkan dengan water bath pada suhu $70^{\circ} \mathrm{C}$. Sementara itu fase air yang berupa gliserin, air demineral, dan trietanolamin (TEA) dipanaskan juga dengan water bath pada suhu $60^{\circ} \mathrm{C}$. Homogenisasi dilakukan dengan cara fase minyak dimasukkan secara perlahan ke dalam fase air menggunakan mixer selama 15 menit. Kecepatan homogenisasi yang digunakan dalam mixer ini adalah $600 \mathrm{rpm}$. Proses secara konvensional ini akan menghasilkan krim biasa. Campuran tersebut diaduk dengan mixer hingga homogen dan suhu dijaga konstan pada kisaran $70{ }^{\circ} \mathrm{C}-80^{\circ} \mathrm{C}$ agar campuran tidak memadat.

Homogenisasi lanjutan dilakukan dengan menggunakan Reaktor PPI untuk menghasilkan krim nanopartikel. Hasil campuran fase lemak dan fase air yang telah dihomogenisasi dengan mixer segera dimasukkan pada wadah reaktor secara perlahan. Minyak zaitun segera dimasukkan juga pada wadah reaktor. Pengaturan suhu pada Reaktor PPI sebesar $72^{\circ} \mathrm{C}$. Kecepatan homogenisasi yang digunakan adalah sebesar 1000 rpm, 1500 rpm, 2000 rpm, dan $2500 \mathrm{rpm}$. Dalam hal ini kecepatan homogenisasi sebagai variabel perubah. Proses ini berlangsung selama 1 jam. Apabila terjadi ketidakstabilan suhu selama proses maka perlu dilakukan pengaturan suhu sampai mendekati $72^{\circ} \mathrm{C}$ sesuai titik leleh fasa lemak (Rahmi et al., 2013). Produk krim nanopartikel dimasukkan ke dalam wadah kaca yang sudah dibersihkan dan disterilkan. Proses selanjutnya adalah wadah kaca ditutup rapat dan disimpan pada suhu ruangan. Selanjutnya produk krim nanopartikel siap untuk dilakukan uji evaluasi.

\section{Uji Evaluasi Krim Nanopartikel}

\section{Uji Organoleptik}

Pengujian organoleptik pada krim meliputi: bentuk, warna, bau, dan homogenitas.

\section{Uji Derajat Keasaman (pH)}

Krim sebanyak $1 \mathrm{~g}$ ditimbang dan diencerkan dengan $10 \mathrm{ml}$ air demineral lalu diaduk dengan menggunakan batang pengaduk. Pengukuran $\mathrm{pH}$ dilakukan dengan menggunakan kertas indikator. Hasil uji $\mathrm{pH}$ sediaan krim yang diharapkan mendekati pH kulit normal yaitu 5,5 (Iswari \& Latifah, 2007) atau kisaran $\mathrm{pH}$ yang dipersyaratkan oleh SNI 16-4399-1996 Sediaan Tabir Surya (pH 4,5-8,0). 


\section{Uji Penentuan Tipe Emulsi Krim Minyak dalam Air (M/A)}

Krim sebanyak 1 gram diteteskan kristal violet. Krim diaduk hingga homogen lalu dioleskan di atas kaca transparan. Pengamatan makroskopik dilakukan secara visual di atas kaca. Pengamatan mikroskopik dilakukan dengan menggunakan mikroskop untuk melihat adanya fase minyak dan fase air sehingga bisa ditentukan tipe emulsi krim. Kristal violet akan terlarut dalam fase air. Jika medium pendispersi berwarna biru merata maka emulsi bertipe (M/A) minyak dalam air (Lachman et al., 2008).

\section{Penentuan Ukuran Partikel}

Krim nanopartikel yang telah dibuat selanjutnya ditentukan ukuran partikelnya dengan menggunakan particle size analyzer (PSA) berdasarkan intensitasnya (Pang et al., 2009). Konsentrasi larutan krim yang digunakan untuk pengujian dengan paticle size analyzer (PSA) adalah 10.000 ppm berdasarkan hasil pengukuran. Air demineral digunakan sebagai medium pendispersi krim.

\section{Uji Stabilitas Emulsi}

Stabilitas emulsi (SE) yang dimaksud dalam penelitian ini adalah fase yang stabil. Sampel dimasukkan ke dalam suatu wadah dan ditimbang bobotnya menggunakan neraca analitik. Uji stabilitas dipercepat ini dilakukan pada suhu $45^{\circ} \mathrm{C}$ dan $0^{\circ} \mathrm{C}$. Wadah dan bahan tersebut dimasukkan ke dalam oven dengan suhu $45^{\circ} \mathrm{C}$ selama 1 jam kemudian dimasukkan ke dalam pendingin bersuhu $0{ }^{\circ} \mathrm{C}$ selama 1 jam. Setelah itu wadah dan bahan dikembalikan lagi ke dalam oven bersuhu $45^{\circ} \mathrm{C}$ selama 1 jam. Pengamatan dilakukan terhadap kemungkinan terjadinya pemisahan air dari emulsi. Apabila terjadi pemisahan maka emulsi dikatakan tidak stabil dan tingkat kestabilannya dihitung berdasarkan persentase fasa terpisahkan terhadap emulsi keseluruhan. Pengujian ini mengacu pada penelitian yang telah dilakukan oleh Rahmi et al., (2013). Stabilitas emulsi atau fase yang stabil dihitung berdasarkan perbadingan berat fase yang tersisa dengan berat total emulsi yang dinyatakan dalam persen.

\section{HASIL DAN PEMBAHASAN}

\section{Pembuatan Krim Nanopartikel dengan Metode High Speed Homogenization (HSH)}

Penelitian ini terdiri atas 2 tahapan utama, yaitu pembuatan krim nanopartikel melalui proses homogenisasi dan pengujian evaluasi krim. Dalam hal ini pengaruh kecepatan homogenisasi dalam pembuatan krim dengan menggunakan Reaktor PPI akan dibandingkan hasilnya melalui uji evaluasi krim. Homogenisasi merupakan proses mengubah dua cairan yang sifatnya tidak bercampur menjadi sebuah emulsi. Efektifitas pengurangan ukuran partikel dengan menggunakan Reaktor PPI dapat dipengaruhi oleh jumlah bahan yang dihomogenisasi, waktu, dan kecepatan homogenisasi.

Metode yang digunakan dalam pembuatan krim nanopartikel ini adalah $\mathrm{HSH}$. Keuntungan dari metode ini adalah mudah untuk di scale up, terhindar dari pelarut organik, dan waktu produksi yang singkat. Krim yang dibuat dalam penelitian dapat digolongkan sebagai nanopartikel lemak. Proses produksi nanopartikel lemak dengan teknik $\mathrm{HSH}$ yang dapat dilakukan dengan 2 metode, yaitu pada suhu dingin dan suhu panas. Proses untuk metode panas yaitu senyawa aktif dilarutkan atau didispersikan ke dalam lelehan lemak padat. Hal ini akan menyebabkan lelehan lemak yang mengandung senyawa aktif tersebar dalam larutan surfaktan pada suhu yang sama (5-10 ${ }^{\circ} \mathrm{C}$ di atas titik leleh dari lemak padat atau campuran lemak) dengan adanya kecepatan pengadukan yang tinggi. Emulsi yang diperoleh umumnya disebut pre-emulsion kemudian dilewatkan melalui homogenizer bertekanan tinggi yang secara umum 3 siklus pada 500 bar dan 3 siklus pada 800 bar. Teknik homogenisasi dengan metode dingin prosesnya yaitu lelehan lemak yang mengandung senyawa aktif didinginkan terlebih dahulu. Setelah terjadi pemadatan massa akan menghasilkan butiran-butiran lemak yang hancur untuk memperoleh lipid micropaticles. Setelah itu lipid micropaticles akan tersebar dalam 
larutan surfaktan dingin menghasilkan presuspension dingin. Suspensi ini dilewatkan melalui homogenizer tinggi pada suhu kamar dengan 5-10 siklus pada 1500 bar (Pardeike etal., 2009).

Penerapan nanopartikel di bidang kosmetik akan lebih baik apabila menggunakan bahan-bahan alam yang tidak memiliki efek samping seperti asam lemak esensial (fatty acid atau fatty alcohol). Secara umum kosmetik dan produk- produk perawatan diri terdiri dari empat bahan utama yang berperan sebagai surfaktan, pengemulsi, agen penstabil produk, dan sebagai emolien atau pelembab. Pembuatan krim dalam penelitian ini menggunakan bahan-bahan alami untuk memberikan jaminan keamanan kesehatan apabila diaplikasikan pada kulit. Setil alkohol sering disebut juga sebagai peningkat konsistensi atau bodying agent (Rowe et al., 2009). Setil alkohol berfungsi sebagai pengemulsi, penstabil, perawatan kulit, emolien, penambah viskositas air dan bukan air serta pembusa. Setil stearil alkohol berfungsi sebagai emolien dan emulgator. Trietanolamin berfungsi sebagai pengatur $\mathrm{pH}$. Air demineral berfungsi sebagai pelarut. Minyak zaitun adalah minyak lemak yang diperoleh dari biji masak olea europaea Linnè (Familia Oleaceae). Minyak zaitun berupa cairan kuning pucat atau kuning kehijauan terang yang berfungsi sebagai pelarut dan perawatan kulit. Gliserin berfungsi sebagai humektan, pelarut, perawatan kulit, dan penambah viskositas. Asam stearat berfungsi sebagai emolien, surfaktan, pengemulsi, dan perawatan kulit (Kodeks Kosmetika Indonesia II 1993).
Produk krim nanopartikel disajikan pada Gambar 1.

Emulsi merupakan sistem yang tidak stabil. Oleh karena itu dibutuhkan dua hal untuk membentuk emulsi stabil, yaitu penggunaan alat mekanis untuk mendispersikan sistem dan penambahan pengemulsi untuk mempertahankan sistem tetap terdispersi. Pembuatan krim dalam penelitian ini sebagian besar menggunakan bahan pengemulsi. Menurut McClement (2004), pengemulsi penting dalam proses homogenisasi yakni untuk menurunkan tegangan antar muka antara fase air dengan fase minyak. Hal ini akan mengakibatkan terjadinya pengurangan energi bebas yang diperlukan untuk mengubah dan mengacaukan droplet serta membentuk coating yang protektif di sekeliling droplet yang akan mencegah koalesen. Cara kerja pengemulsi dapat diilustrasikan sebagai berikut: bila butir- butir lemak telah terpisah karena adanya tenaga mekanik (pengadukan), maka butir- butir lemak yang terdispersi tersebut segera terselubungi oleh selaput tipis pengemulsi. Bagian molekul pengemulsi yang nonpolar larut dalam lapisan luar butir- butir lemak sedangkan bagian yang polar menghadap ke pelarut seperti air (Mc Clements, 2004).

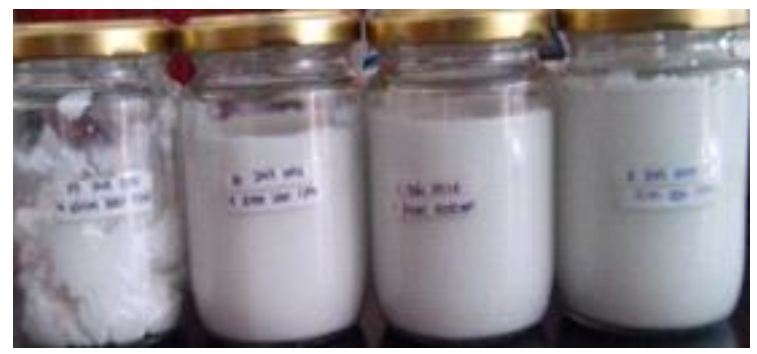

Gambar 1. Krim nanopartikel

Tabel 1. Hasil uji organoleptik krim nanopartikel

\begin{tabular}{ccccc}
\hline $\begin{array}{c}\text { Kecepatan } \\
\text { Homogenisasi (rpm) }\end{array}$ & Bentuk & Warna & Bau & Homogenitas \\
\hline 1000 & emulsi padat & Putih & khas minyak & homogen \\
1500 & emulsi padat & Putih & khas minyak & homogen \\
2000 & emulsi padat & Putih & khas minyak & homogen \\
2500 & emulsi padat & Putih & khas minyak & homogen \\
\hline
\end{tabular}

\section{Organoleptik krim nanopartikel}

Uji organoleptik dimaksudkan untuk mengetahui tampilan fisik suatu krim yang meliputi bentuk, warna, bau dan homogenitas. Pengujian ini dilakukan secara visual tanpa bantuan alat khusus. Hasil uji organoleptik (Tabel 1) diperoleh krim 
dengan wujud padat, berwarna putih sesuai dengan bahan fase lemak, berbau khas seperti minyak, dan homogen. Perubahan bau pada krim dapat terjadi apabila ada paparan cahaya matahari yang berperan sebagai katalisator dan oksigen dari udara terhadap minyak atau lemak. Hal tersebut akan menyebabkan percepatan oksidasi lemak sehingga terjadi ketengikan atau perubahan bau yang tidak sedap. Dalam penelitian ini dilakukan penyimpanan krim di tempat yang tidak terpapar cahaya matahari dan pada suhu kamar. Krim yang disimpan selama 2 bulan menunjukkan tidak terjadinya perubahan bau, warna, dan pemisahan fase.

Uji homogenitas bertujuan untuk melihat dan mengetahui tercampurnya bahan-bahan krim. Pengujian ini dilakukan secara visual dengan cara mengoleskan krim pada kulit dan mengamati rata atau tidaknya bahan krim. Hasil penelitian menunjukkan tidak adanya gumpalangumpalan atau pemisahan fase. Krim yang tidak mengalami pemisahan fase ini dimungkinkan bahan-bahan telah tercampur secara homogen dan jumlah pengemulsi yang digunakan cukup untuk menstabilkan emulsi. Perbedaan kecepatan pengaduk pada reaktor ternyata memengaruhi tampilan fisik krim dari segi tekstur. Semakin besar kecepatan pengaduk pada reaktor maka semakin halus pula tekstur krim yag dihasilkan (Muller-Fischer et al., 2006). Krim yang dibuat pada kecepatan pengaduk 2500 rpm merupakan krim dengan tekstur yang paling lembut.

\section{Derajat Keasaman (pH)}

Nilai pH merupakan salah satu parameter penting dalam produk kosmetika. Nilai $\mathrm{pH}$ adalah derajat keasaman suatu bahan atau pengukuran aktivitas hidrogen dalam lingkungan air. Menurut Iswari dan Latifah (2007), pH produk kosmetik sebaiknya mendekati pH kulit, yaitu 5,5. Produk kosmetika yang memiliki $\mathrm{pH}$ yang jauh dengan $\mathrm{pH}$ fisiologis kulit sekitar 4,5-5,5 akan lebih mudah mengiritasi kulit. Kulit dilapisi oleh mantel asam yaitu lapisan lembab yang bersifat asam di permukaan kulit. Mantel asam ini terbentuk dari asam lemak yang berasal dari minyak kulit, asam susu dalam keringat serta asam amino. Mantel asam ini berfungsi melindungi kulit dari kekeringan, infeksi bakteri dan jamur. Mantel asam akan rusak bila sering terkena bahan atau kosmetika yang mempunyai $\mathrm{pH}$ jauh berbeda dengan $\mathrm{pH}$ fisiologis kulit. Pengujian $\mathrm{pH}$ krim dalam penelitian ini bertujuan untuk mengetahui keamanan krim saat digunakan sehingga tidak mengiritasi kulit. Menurut Dahanayake dan Rosen (2000), iritasi kulit merupakan proses terjadinya denaturasi protein yang disebabkan oleh adsorpsi surfaktan oleh kulit. Dalam pembuatan krim ini perlu diperhatikan jenis surfaktan, kecenderungan surfaktan untuk menyerap ke kulit, dan kemudahan surfaktan dalam menembus sel membran kulit. Hal inilah yang akan menjadi faktor penentu utama terjadinya iritasi kulit.

Pengujian $\mathrm{pH}$ ini dilakukan dengan menggunakan $\mathrm{pH}$ indikator universal. Kertas $\mathrm{pH}$ indikator universal dimasukkan ke dalam krim kemudian dicocokkan warna indikator dengan standar warna $\mathrm{pH}$ indikator yang tertera pada wadahnya. Uji pH terhadap krim dengan kecepatan homogenisasi $1000 \mathrm{rpm}$, 1500 rpm, 2000 rpm, dan 2500 rpm ternyata diperoleh nilai $\mathrm{pH}$ yang sama, yaitu sebesar 6. Nilai $\mathrm{pH}$ ini masih dalam kisaran $\mathrm{pH}$ yang dipersyaratkan oleh SNI 16-4399-1996 Sediaan Tabir Surya, yaitu pH 4,5-8,0. Pengujian $\mathrm{pH}$ ini dilakukan selama 2 bulan penyimpanan krim pada suhu kamar. Hasil menunjukkan bahwa tidak terjadi perubahan pH pada krim.

Perubahan $\mathrm{pH}$ dapat terjadi pada krim apabila terjadi perubahan suhu pada tempat penyimpanan. Menurut Budiman (2008), krim yang disimpan dalam suhu tinggi sekitar $40 \pm 2^{\circ} \mathrm{C}$ akan mengalami perubahan $\mathrm{pH}$ ke arah asam. Hal ini disebabkan oleh terjadinya proses hidrolisis karena adanya peningkatan suhu. Nilai $\mathrm{pH}$ krim tidak boleh terlalu asam karena dapat menyebabkan iritasi pada kulit dan jika $\mathrm{pH}$ terlalu basa maka dapat menyebabkan kulit bersisik. Berdasarkan pernyataan tersebut dapat disimpulkan bahwa penyimpanan krim menjadi salah satu faktor yang harus diperhatikan untuk menjaga kualitas produk kosmetik. 


\section{Penentuan Tipe Emulsi Krim Minyak dalam Air (M/A)}

Emulsi merupakan bahan yang mengandung dua fase yang tidak bercampur, biasanya air dan minyak dengan cairan yang satu terdispersi menjadi tetesan- tetesan kecil (droplet) dalam cairan lainnya yang distabilkan dengan zat pengemulsi atau surfaktan yang cocok. Fase yang berbentuk droplet disebut fase terdispersi, fase internal atau fase diskontinyu. Fase cairan tempat droplet terdispersi disebut fase pendispersi, fase eksternal atau fase kontinyu (Anief, 2000). Fase minyak dalam penelitian ini sebagai fase terdispersi dan fase air sebagai fase pendispersi. Krim yang dihasilkan dalam penelitian ini termasuk tipe emulsi minyak dalam air (M/A) disebut juga sebagai krim basis hidrofilik. Hal ini disebabkan perbandingan jumlah fase air lebih besar daripada fase minyak sehingga dapat diencerkan dengan air (Agoes, 2008).
Penentuan tipe emulsi krim dalam penelitian ini dilakukan dengan cara menambahkan pereaksi kristal violet pada krim secara makroskopik dan mikroskopik. Hasil pengamatan makroskopik krim nanopartikel (Gambar 2) dilakukan secara visual. Krim yang berwarna putih berubah menjadi ungu karena adanya kristal violet. Pereaksi kristal violet ini akan larut dalam air sehingga hanya membasahi medium pendispersi pada tipe emulsi (M/A) minyak dalam air. Pengamatan mikroskopik krim nanopartikel (Gambar 3) bertujuan untuk memastikan dispersi kristal violet dalam krim. Hasil menunjukkan bahwa kristal violet terdispersi secara merata dalam medium pendispersi yaitu fase air. Hal ini mengakibatkan medium pendispersi berwarna ungu. Berdasarkan pernyataan tersebut maka tipe emulsi krim adalah minyak dalam air (M/A) (Lachman et al., 2008). Dalam hal ini menunjukkan kristal violet tidak dapat larut dalam fase minyak.

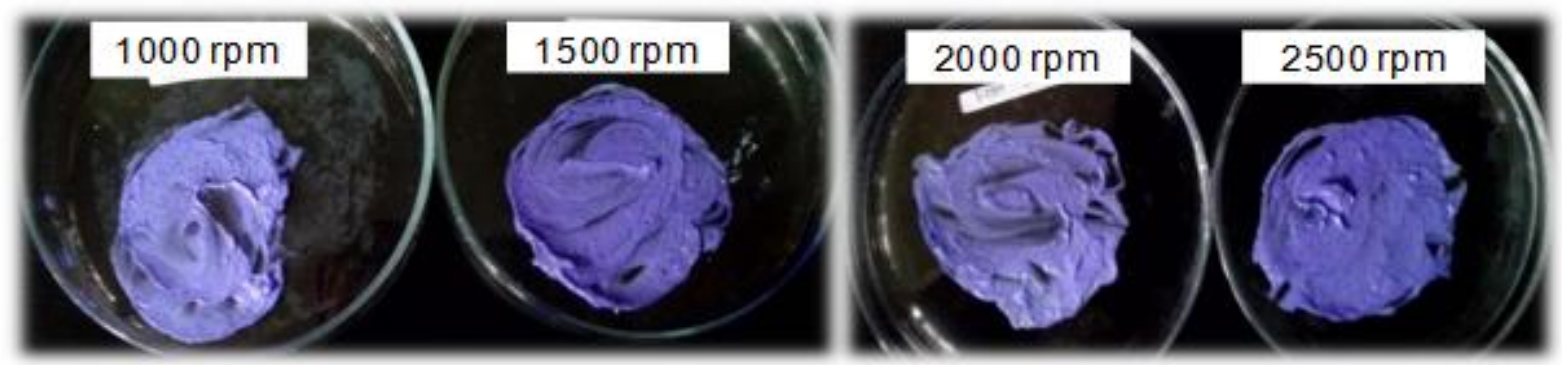

Gambar 2. Hasil pengamatan makroskopik krim nanopartikel

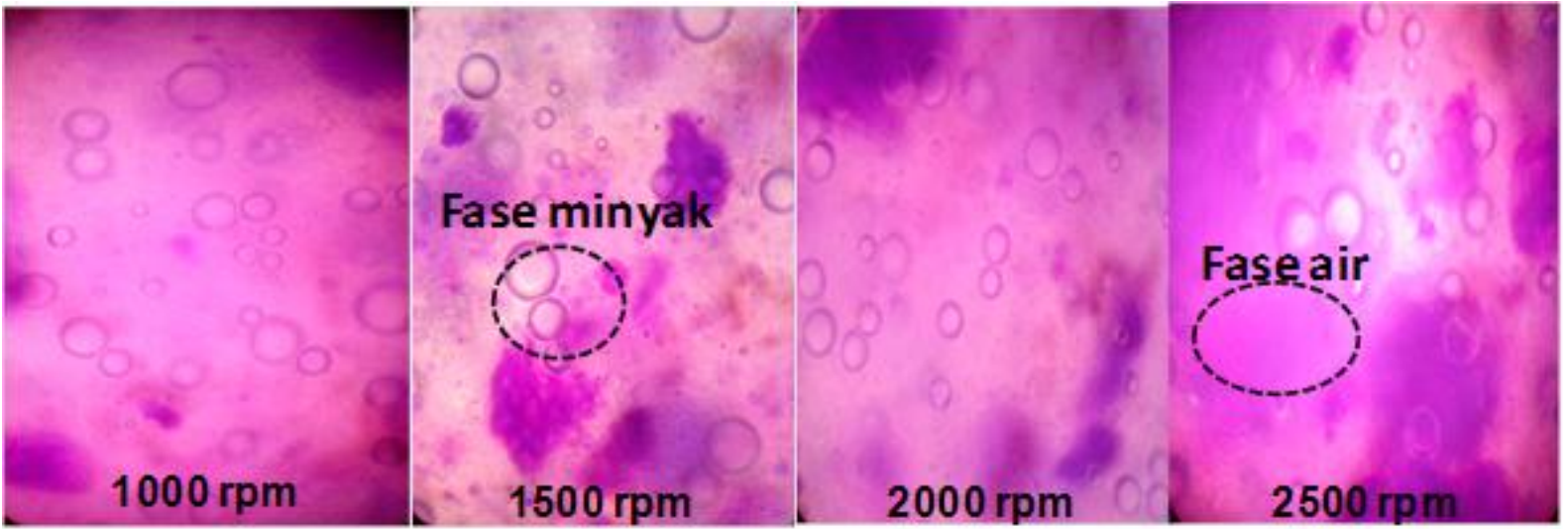

Gambar 3. Hasil pengamatan mikroskopik krim nanopartikel perbesaran 400 kali

Berdasarkan penelitian ini diamati pengaruh kehomogenan partikel dalam krim. Semakin kecil ukuran droplet maka semakin homogen emulsi yang dihasilkan. Kehomogenan emulsi ini erat kaitannya dengan stabilitas emulsi. Menurut Suryani et al., (2000), pembentukan emulsi yang stabil dipengaruhi oleh konfigurasi partikel fase terdispersi dalam medium pendispersi. Semakin kecil ukuran partikel fase 
terdispersi maka konfigurasi partikel fase terdispersi dalam medium pendispersi akan semakin teratur. Keseragaman ukuran partikel pada fase terdispersi dapat diketahui melalui pengamatan mikroskopik. Pengamatan mikroskopik menunjukkan bahwa ukuran partikel tetesan minyak pada fase terdispersi tidak seragam. Adanya perbedaan ukuran partikel dalam pengamatan mikroskopik ini menunjukkan ciri ketidakstabilan krim. Ketidaktabilan nanopartikel lemak dalam krim kosmetik disebabkan oleh adanya droplet (butiranbutiran minyak) yang mengalami agregasi atau pemecahan (Müller et al., 2007).

\section{Pengukuran Distribusi dan Ukuran Partikel}

Distribusi dan ukuran partikel merupakan salah satu bagian dari karakterisasi nanopartikel. Ukuran partikel akan mempengaruhi secara langsung terhadap keunikan sifat dari nanopartikel. Oleh sebab itu, penentuan distribusi dan ukuran partikel dalam penelitian ini perlu dilakukan untuk mengetahui perbedaan hasil perlakuan homogenisasi terhadap kondisi partikel emulsi. Beberapa teknik yang dapat digunakan untuk menentukan ukuran partikel, di antaranya photon correlation spectroscopy (PCS), transmission electron microscopy (TEM), scanning electron microscopy (SEM), atomic force microscopy (AFM), dan scanning tunneling microscopy (STM). Pengukuran partikel dengan metode PCS biasanya menggunakan metode basah, yaitu menggunakan media pendispersi untuk mendispersikan material uji. Metode ini lebih akurat jika dibandingkan dengan metode kering ataupun pengukuran partikel dengan metode ayakan dan analisa gambar untuk sampel-sampel berukuran kecil.

Distribusi dan ukuran partikel dalam penelitian ini dianalisa dengan menggunakan particle size analyzer (PSA). Pengukuran PSA ini didasarkan pada prinsip metode dynamic light scattering. Metode dynamic light scattering atau sering disebut PCS ini merupakan teknik terbaik untuk pengukuran rutin ukuran partikel (Menhnert \& Mader, 2001). Pengukuran menggunakan PSA lebih akurat dibandingkan dengan scanning electron microscope (SEM) terutama untuk sampel-sampel dalam orde nanometer dan submikron yang memiliki kecenderungan aglomerasi yang tinggi (Lidiyah, 2011). Hasil pengukuran PSA berbentuk distribusi atau sebaran sehingga dapat digunakan untuk menentukan ukuran partikel. Metoda PCS mencakup rentang ukuran dari beberapa nanometer sampai 3 mikrometer. Partikel- partikel lebih kecil menyebabkan penghamburan yang lebih kuat pada sudut besar dibandingkan dengan partikel lebih besar. Keuntungan dari metode ini adalah analisis yang cepat, tidak memerlukan kalibrasi, dan peka terhadap partikel submikron (Menhnert \& Mader, 2001). Keuntungan lainnya menurut Rawie (2010), ukuran partikel yang terukur adalah ukuran dari partikel tunggal akibat pendispersian partikel ke dalam media. Hasil pengukuran yang didapat juga berada dalam bentuk distribusi partikel, sehingga dapat menggambarkan keseluruhan kondisi sampel. Sampel-sampel dalam ukuran nanometer dan submikron memiliki kecenderungan aglomerasi yang tinggi. Pengukuran dengan alat PSA dalam penelitian ini menggunakan suhu ruang. Suhu ini akan mempengaruhi gerakan partikel dalam larutan selama pengukuran. Semakin tinggi suhu maka gerak partikel akan semakin aktif. Hal ini akan berpengaruh terhadap keakuratan hasil pengukuran. Sebaran partikel dari sampel yang diuji dengan PSA dapat ditunjukkan berdasarkan jumlah, volume, dan intensitas sampel. Metode penghitungan partikel yang terdapat pada alat PSA terdiri dari 3 metode, di antaranya: pade-laplace, statistik, dan cumulants. Hasil uji PSA atau sebaran partikel dari krim nanopartikel disajikan pada Gambar 4 dan Tabel 2.

Karakteristik dari sebaran partikel yang digunakan pada penelitian ini berdasarkan pada sebaran partikel dalam intensitas (intensity) dengan metode cumulants. Nilai sumbu y pada grafik menunjukkan banyaknya partikel yang terukur pada alat PSA dan sumbu $x$ menunjukkan rentang ukuran dari sampel yang diuji. Hasil analisa particle size analyzer (PSA) krim ini menghasilkan ukuran partikel dengan nilai yang berfluktuasi. Ukuran partikel semakin meningkat pada perlakuan kecepatan homogenisasi $2000 \mathrm{rpm}$ dan $2500 \mathrm{rpm}$. Hal ini disebabkan tingkat kestabilan krim masih 
rendah akibat terjadinya aglomerasi dan adanya destabilitas emulsi. Ukuran partikel dalam krim nanopartikel penelitian ini berkisar 239,86-358,10 nm. Hal ini ternyata sesuai dengan ASTM Committee E56 on Nanotechnology yang menyatakan bahwa ukuran krim nanopartikel berkisar 200-300 $\mathrm{nm}$. Krim yang dihasilkan ini dapat dikategorikan sebagai nanopartikel lemak padat. Oleh sebab itu, ukuran tersebut ternyata masih dalam rentang ukuran nanopartikel lemak padat yang baik yaitu 50 $1000 \mathrm{~nm}$ (Musthaba et al., 2009).

Kecepatan putaran homogenizer berpengaruh terhadap distribusi ukuran partikel. Semakin meningkatnya kecepatan putaran homogenizer, seharusnya ukuran partikel emulsi yang dihasilkan semakin kecil. Input energi berpengaruh secara langsung terhadap ukuran partikel. Namun dalam penelitian ini hubungan antara kecepatan homogenisasi dengan ukuran partikel tidak sesuai dengan teori MüllerFischer et al., (2006) yang menyatakan bahwa semakin besar peningkatan gaya kinetik yang diberikan akan menghasilkan ukuran partikel yang semakin kecil. Faktor yang mungkin terjadi dalam pengujian PSA ini adalah waktu homogenisasi yang belum optimum, adanya kontaminan pada preparasi sampel sehingga cairan krim belum homogen secara merata.
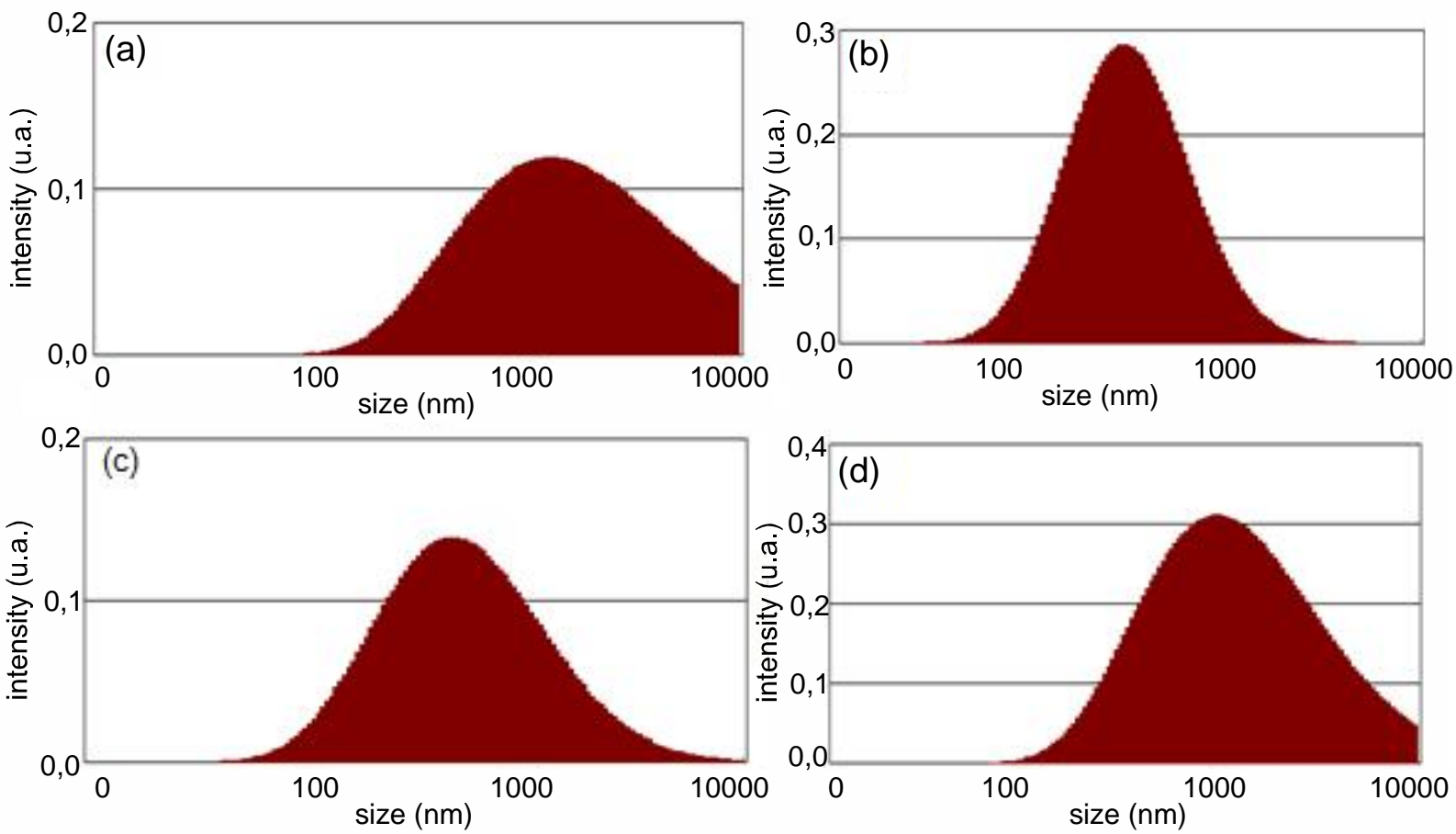

Gambar 4. Hasil uji PSA krim nanopartikel dengan kecepatan homogenisasi (a) 1000 rpm,

(b) $1500 \mathrm{rpm}$, (c) $2000 \mathrm{rpm}$, (d) $2500 \mathrm{rpm}$

Tabel 2. Hasil pengukuran distribusi dan ukuran partikel krim nanopartikel

\begin{tabular}{ccc}
\hline $\begin{array}{c}\text { Kecepatan homogenisasi } \\
(\mathrm{rpm})\end{array}$ & Rentang ukuran $(\mathrm{nm})$ & Rerata ukuran partikel $(\mathrm{nm})$ \\
\hline 1000 & $141,29-9.774,96$ & 297,04 \\
1500 & $40,75-2.571,08$ & 239,86 \\
2000 & $64,58-5.890,00$ & 302,14 \\
2500 & $93,35-9.774,96$ & 358,10 \\
\hline
\end{tabular}

Cara yang dapat dilakukan untuk menghasilkan ukuran droplet emulsi yang diperkecil yaitu dengan meningkatkan jumlah energi yang diberikan selama proses 
emulsifikasi, selama masih tersedia pengemulsi yang cukup untuk menyelimuti permukaan droplet yang baru terbentuk. Ukuran partikel dipengaruhi oleh berbagai faktor yang terjadi selama proses pembuatan emulsi seperti pengadukan atau pencampuran dan juga dipengaruhi oleh jumlah pengemulsi. Menurut McClements (2004), beberapa faktor yang mempengaruhi ukuran droplet yang dihasilkan oleh homogenisasi yaitu tipe emulsi yang digunakan, suhu karakter komponen fasefasenya, dan masukan energi. Ukuran droplet kecil yang dihasilkan oleh homogenisasi dapat menimbulkan fase terdispersi. Sebagai akibatnya viskositas semakin meningkat dan penyerapan emulsifier dapat meningkat. Ketidakcukupan emulsifier dalam menyelubungi permukaan droplet-droplet akan menyebabkan koalesen. Intensitas dan lama proses pencampuran tergantung waktu yang diperlukan untuk melarutkan dan mendistribusikan secara merata.

\section{Stabilitas Emulsi (Fase yang Stabil)}

Stabilitas emulsi merupakan kestabilan suatu bahan dengan emulsi yang terdapat dalam bahan tidak mempunyai kecenderungan untuk bergabung dengan partikel lain dan membentuk lapisan yang terpisah. Sistem emulsi pada dasarnya adalah suatu sistem yang tidak stabil. Hal ini disebabkan masing-masing partikel mempunyai kecenderungan untuk bergabung dengan partikel sesama lainnya membentuk suatu agregat yang akhinya dapat mengakibatkan emulsi tersebut pecah. Kekuatan dan kekompakan lapisan antar muka adalah sifat yang penting dalam pembentukan stabilitas emulsi (Suryani et al., 2000). Kestabilan emulsi merupakan proses pemisahan emulsi yang berjalan lambat sehingga proses tersebut tidak teramati selama selang waktu yang diinginkan.

Pada penelitian ini dianalisis hubungan pengaruh kecepatan homogenisasi terhadap stabilitas emulsi atau fase yang stabil (Gambar 5). Kecepatan homogenisasi yang semakin meningkat seharusnya akan menghasilkan stabilitas emulsi yang semakin meningkat pula. Hasil rata-rata stabilitas emulsi krim berada pada kisaran $97 \%$ hingga $98 \%$. Nilai stabilitas emulsi yang paling tinggi adalah krim dengan perlakuan kecepatan homogenisasi 1000 rpm. Kestabilan emulsi krim semakin menurun seiring dengan meningkatnya kecepatan homogenisasi hingga 2000 rpm. Akan tetapi terjadi peningkatan kestabilan emulsi pada kecepatan homogenisasi 2500 rpm. Menurut McClement (2004), kecepatan putaran homogenizer yang semakin besar dan waktu homogenisasi yang semakin lama akan menghasilkan energi yang semakin besar untuk membuat pengemulsi lebih mampu menstabilkan droplet pada produk emulsi. Berdasarkan pernyataan tersebut dapat dikatakan bahwa pengaruh kecepatan homogenisasi terhadap stabilitas emulsi dalam penelitian ini tidak berbanding lurus. Hal ini disebabkan nilai stabilitas emulsi berfluktuasi.

Fluktuasi nilai stabilitas emulsi (fase yang stabil) dalam penelitian ini menunjukkan bahwa emulsi krim tidak stabil. Menurut Mc Clement (2004), faktor-faktor internal yang memengaruhi stabilitas emulsi, di antaranya: tipe dan konsentrasi bahan pengemulsi, jenis dan konsentrasi komponen-komponen fase terdispersi dan fase pendispersi, viskositas fase pendispersi, perbandingan fase terdispersi terhadap fase pendispersi, dan ukuran partikel. Faktor-faktor eksternal yang mempengaruhi stabilitas emulsi adalah pengadukan atau kecepatan putaran homogenisasi yang tidak dapat terkontrol dengan baik, penguapan, dan suhu.

Kerusakan atau destabilitas emulsi terjadi melalui 3 mekanisme utama yaitu kriming, flokulasi, dan koalesen. Kriming merupakan proses pemisahan yang terjadi akibat gerakan-gerakan ke atas/ ke bawah. Hal ini dapat terjadi karena gaya gravitasi terhadap fase-fase yang berbeda densintasnya. Flokulasi merupakan agregasi dari droplet. Pada flokulasi tidak terjadi pemusatan film antar permukaan sehingga jumlah dan ukuran droplet tetap, terjadinya flokulasi akan mempercepat terjadinya kriming. Koalesen adalah penggabungan droplet-droplet menjadi droplet yang lebih besar. Pada tahap ini terjadi pemusatan film antar permukaan sehingga ukuran droplet berubah. 


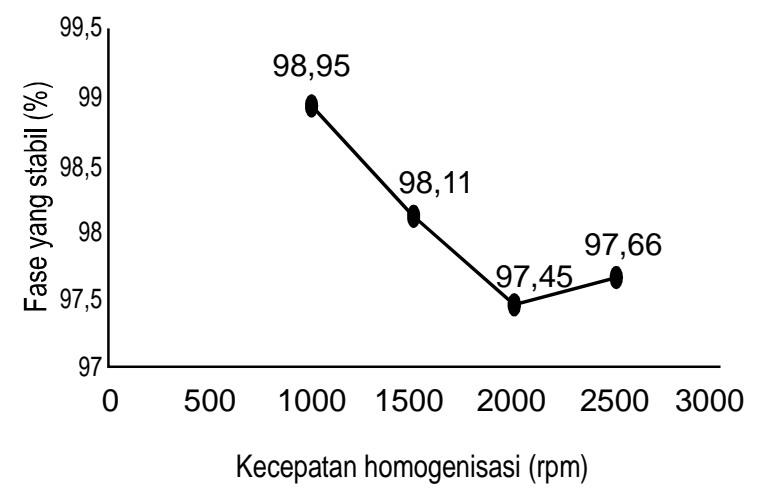

Gambar5. Hubungan kecepatan homogenisasi dengan fase yang stabil

\section{KESIMPULAN}

Krim nanopartikel dengan bentuk padat, putih, berbau khas minyak, dan homogen telah berhasil dibuat secara high speed homogenization (HSH). Uji evaluasi menunjukkan tipe emulsi krim nanopartikel adalah minyak dalam air $(\mathrm{M} / \mathrm{A})$ dan nilai $\mathrm{pH}$ krim masih dalam rentang $\mathrm{pH}$ yang disyaratkan oleh SNI 16-4399-1996 Sediaan Tabir Surya, yaitu pH 4,5-8,0. Selain itu, hasil uji distribusi dan ukuran partikel menunjukkan bahwa krim dalam penelitian ini dapat dikategorikan sebagai krim nanopartikel sesuai ASTM Committee E56 on Nanotechnology dengan kisaran ukuran partikel 200-300 nm. Pengaruh kecepatan homogenisasi terhadap ukuran partikel dan stabilitas emulsi menghasilkan nilai yang berfluktuasi sehingga tidak sesuai dengan hipotesa Müller-Fischer et al., (2006). Hipotesa tersebut adalah semakin besar peningkatan gaya kinetik (kecepatan homogenisasi) yang diberikan maka ukuran partikel akan semakin kecil. Ukuran partikel yang semakin kecil menunjukkan tingkat stabilitas emulsi yang tinggi.

\section{UCAPAN TERIMA KASIH}

Penulis menyampaikan terima kasih kepada Bapak Umar Habson selaku kepala BBKK yang sudah memfasilitasi pelaksanaan penelitian di laboratorium riset kimia BBKK dan Bapak Ahmad Sjahriza yang sudah memberi masukan dan saran dalam perbaikan hasil penelitian.

\section{DAFTAR PUSTAKA}

Agoes, G. 2008. Pengembangan sediaan farmasi edisi revisi dan perluasan. Bandung (ID): ITB.

Anief, M. 2000. I/mu meracik obat. Yogyakarta(ID): UGM Pr.

Ansel, H. C. 2005. Pengantar bentuk sediaan farmasi Ed ke-8. Jakarta (ID): UI Pr.

Anwar, E. 2012. Eksipien dalam sediaan farmasi (Karakterisasi dan Aplikasi). Jakarta (ID): Dian Rakyat.

[ASTM] American Standar Testing Material. 2014. Committee E56 on Nanotechnology. Philadelphia (US): ASTM.

Awad, T., Helgason, T., Kristbergsson, K., Decker, E. A., Weiss, J., Mc Clements, D. J. 2008. Solid lipid nanoparticles as delivery systems for bioactive food components. Food Biophysics. 3:146-154

Balsam, M. S., SD Gerson, MM Rieger, E Sagarin, Sj Strianse. 1972. Cosmetics: Science and Technology. New York (US): J Wiley.

Budiman, M. H. 2008. Uji stabilitas fisik dan aktivitas antioksidan sediaan krim yang mengandung ekstrak kering tomat (Solanum lycopersicum L.) [skripsi]. Depok (ID): FMIPA Universitas Indonesia.

Dahayanake, M., Rosen, M. J. 2000. Industrial utilization of surfactants: Princples and Practice. Urbana (US): AOCS Pr.

[Depkes RI]. Departemen Kesehatan Republik Indonesia. 1976. Peraturan

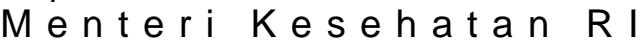
no.220/MenKes/Per/IX/76 tentang Produksi dan Peredaran Kosmetika dan Alat Kesehatan Menteri Kesehatan Republik Indonesia. Jakarta (ID): Depkes RI. 
Iswari, R. \& Latifah, F. 2007. Buku pegangan ilmu pengetahuan kosmetik. Jakarta (ID): Gramedia Pustaka Utama.

Kodeks Kosmetika Indonesia Ed ke-1.1993. Volume 3.

Lachman, L., Lieberman, H. A., Kanig, J. L. 2008. Teori dan praktek farmasi industri II Ed ke-3. Jakarta (ID): Universitas Indonesia Pr.

Lidiyah. 2011. Peningkatan jumlah nanopartikel kitosan terisi ketoprofen berdasarkan ragam surfaktan dan kondisi ultrasonikasi [skripsi]. Bogor (ID): Sekolah Pascasarjana. Institut Pertanian Bogor.

Mc Clements, D. J. 2004. Food emulsion principle, practices, and techniques. New York(US): CRC Pr.

Medha, D. J., Wedny, J. U., Gert, S., Yvette, Vk., Enrico, M. 2012. Journal of controlled release. 161(4): 25-37.

Menhnert, W., Mader, K. 2001. Advanced drug delivery. 47: 165-196

Müller-Fischer, N., Suppiger, D., Windhab, E. J. 2006. Impact of static pressure and volmetric energy input on the microstructure of food foam whipped in a rotor-stator device. J. Food Engineering. 80 : 306-316.

Müller, Rh., Hommoss, A., Pardeike, J., Schmidt, C. 2007. Lipid nanoparticles (NLC) as novel carrier for cosmeticspesial feature \& state of commercialisation. SÖFW-J.40-46.

Musthaba, M. S., Sanjula, B., Sayeed, A., Alka, A., Javed, A. 2009. Status of novel drug delivery technology for phytotherapeutics. India (IN) : Hamdard University.

Nagarajan, R. 2008. Nanoparticles: Building blocks of nanotechnology. Di dalam:
Nagarajan $R$ \& Hatton TA, editor. Nanoparticles: Synthesis, Stabilization, Passivation, and Functionalization. Proceedings of the Symposium at the 233rd Meeting on the American Chemical Society; Chicago, 25-29 Maret 2007. Washington: American Chemical Society. hlm. 2-15.

Pang, X., Cui, F., Tian, J., Chen, J., Zhou, J., Zhou, W. 2009. Preparation and characterization of magnetic solid lipid nanoparticles loaded with ibuprofen. Asian Journal of Pharmaceutical Science 4:132-137.

Pardeike, J., Hommonss, A., Müller, R. H. 2009. Lipid nanoparticles (SLN, NLC) in cosmetics and pharmaceutical dermal products. International Journal of Pharmaceutics. 170-184.

Rahmi, D., Yunilawati, R., Ratnawati, E. 2013. Peningkatan stabilitas emulsi krim nanopartikel untuk mempertahankan kelembaban kulit. $J$. Kimia dan Kemasan. 35(1): 30-36.

Rawie, A. 2010. Technical Paper: Basic principles of particle size analysis. worcestershire (GB): Malvern Instruments Limited.

Rowe, R. C., Sheskey, P. J., Quinn, M. E. 2009. Handbook of pharmaceutical excipients. London (UK): Pharmaceutical Press and American Pharmaceutical Association.

[SNI] Standar Nasional Indonesia. 2005. Sediaan tabir surya. SNI 16-43991996. Jakarta (ID): Badan Standardisasi Nasional.

Suryani, A., Sailah, I., Hambali, E. 2000. Teknologiemulsi. Bogor (ID): IPB.

Thassu, D., Pathak, Y., Deleers, M. 2007. Nanoparticulate drug-delivery system. New York (US): Informa. 